\title{
Sustained Improvement of Left Ventricular Strain following Transcatheter Aortic Valve Replacement
}

Lozano Granero, Vanesa Cristina ; Fernández Santos, Sara ; Fernández-Golfín, Covadonga ; González Gómez, Ariana ; Plaza Martín, María ; de la Hera Galarza, Jesús María ; Faletra, Francesco Fulvio ; Swaans, Martin J ; López-Fernández, Teresa ; Mesa, Dolores ; La Canna, Giovanni ; Echeverría García, Tomás ; Habib, Gilbert ; Martínez Monzonís, Amparo ; Zamorano Gómez, José Luis

\begin{abstract}
Purpose: Left ventricular (LV) mechanics are impaired in patients with severe aortic stenosis (AS). Transcatheter aortic valve replacement (TAVR) has become a widespread technique for patients with severe AS considered inoperable or high risk for open surgery. This procedure could have a positive impact in LV mechanics. The aim of the study was to evaluate the effect of TAVR on LV function recovery, as assessed by myocardial deformation parameters, both immediately and in the long term. Methods: One-hundred nineteen consecutive patients ( $81.2 \pm 6.9$ years, $50.4 \%$ female) from 10 centres in Europe with severe AS who successfully underwent TAVR with either a self-expanding CoreValve (Medtronic, Minneapolis, MN, USA) or a mechanically expanded Lotus valve (Boston Scientific, Natick, MA, USA) were enrolled in a prospective observational study. A complete echocardiographic examination was performed prior to device implantation, before discharge and 1 year after the procedure, including the assessment of LV strain using standard 2D images. Results: Between baseline and discharge, only a modest but statistically significant improvement in GLS (global longitudinal strain) could be seen (GLS\% $-14.6 \pm 5.0$ at baseline; $-15.7 \pm 5.1$ at discharge, $\mathrm{p}=0.0116$ ), although restricted to patients in the CoreValve group; 1 year after the procedure, a greater improvement in GLS was observed (GLS\% - 17.1 $\pm 4.9, \mathrm{p}<0.001)$, both in the CoreValve and the Lotus groups. Conclusions: Immediate and sustained improvement in GLS was appreciated after the TAVR procedure. Whether this finding continues to be noted in a more prolonged follow-up and its clinical implications need to be assessed in further studies.
\end{abstract}

DOI: https://doi.org/10.1159/000500633

Posted at the Zurich Open Repository and Archive, University of Zurich

ZORA URL: https://doi.org/10.5167/uzh-182208

Journal Article

Published Version

Originally published at:

Lozano Granero, Vanesa Cristina; Fernández Santos, Sara; Fernández-Golfín, Covadonga; González Gómez, Ariana; Plaza Martín, María; de la Hera Galarza, Jesús María; Faletra, Francesco Fulvio; Swaans, Martin J; López-Fernández, Teresa; Mesa, Dolores; La Canna, Giovanni; Echeverría García, Tomás; Habib, Gilbert; Martínez Monzonís, Amparo; Zamorano Gómez, José Luis (2019). Sustained Improvement of Left Ventricular Strain following Transcatheter Aortic Valve Replacement. Cardiology, 143(1):52-61.

DOI: https://doi.org/10.1159/000500633 


\title{
Sustained Improvement of Left Ventricular Strain following Transcatheter Aortic Valve Replacement
}

\author{
Vanesa Cristina Lozano Granero ${ }^{a}$ Sara Fernández Santos ${ }^{a}$ \\ Covadonga Fernández-Golfín ${ }^{b}$ Ariana González Gómez ${ }^{a}$ María Plaza Martín ${ }^{a}$ \\ Jesús María de la Hera Galarzac Francesco Fulvio Faletrad Martin J. Swaans ${ }^{\text {e }}$ \\ Teresa López-Fernández ${ }^{f}$ Dolores Mesa ${ }^{g}$ Giovanni La Cannah \\ Tomás Echeverría Garcíai Gilbert Habibj Amparo Martínez Monzonís ${ }^{k}$ \\ José Luis Zamorano Gómez ${ }^{a} \quad$ SITAR (Strain Imaging in Transcatheter \\ Aortic-Valve Replacement) group

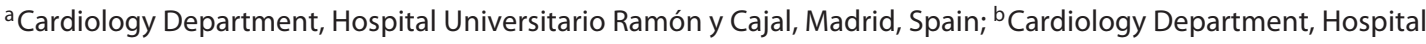
Universitario Ramón y Cajal, CIBERCV, Madrid, Spain; ' Cardiology Department, Hospital Universitario Central

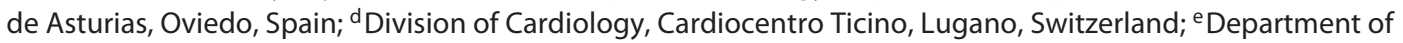
Cardiology, St. Antonius Hospital, Nieuwegein, The Netherlands; ${ }^{f}$ Cardiology Department, Hospital Universitario La Paz, IdiPaz, Madrid, Spain; ${ }^{9}$ Cardiology Department, Hospital Universitario Reina Sofía, Córdoba, Spain;

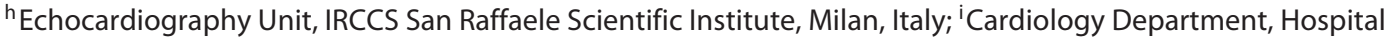
Universitario Donostia, Guipzcoa, Spain; ${ }^{j}$ Cardiology Department, Hôpital de la Timone, Marseille, France; ${ }^{k}$ Complexo Hospitalario Universitario de Santiago, Santiago de Compostela, Spain
\end{abstract}

\section{Keywords}

Strain · Left ventricular mechanics · Echocardiography · Aortic stenosis · Transcatheter aortic valve replacement

\begin{abstract}
Purpose: Left ventricular (LV) mechanics are impaired in patients with severe aortic stenosis (AS). Transcatheter aortic valve replacement (TAVR) has become a widespread technique for patients with severe AS considered inoperable or high risk for open surgery. This procedure could have a positive impact in LV mechanics. The aim of the study was to evaluate the effect of TAVR on LV function recovery, as as-
\end{abstract}

(๑) 2019 S. Karger AG, Basel

\section{E-Mail karger@karger.com \\ www.karger.com/crd \\ KARGER}

sessed by myocardial deformation parameters, both immediately and in the long term. Methods: One-hundred nineteen consecutive patients ( $81.2 \pm 6.9$ years, $50.4 \%$ female) from 10 centres in Europe with severe AS who successfully underwent TAVR with either a self-expanding CoreValve (Medtronic, Minneapolis, MN, USA) or a mechanically expanded Lotus valve (Boston Scientific, Natick, MA, USA) were enrolled in a prospective observational study. A complete echocardiographic examination was performed prior to device implantation, before discharge and 1 year after the procedure, including the assessment of LV strain using standard 2D images. Results: Between baseline and discharge, only a modest but statistically significant improvement in GLS

Vanesa Cristina Lozano Granero, MD

Cardiology Department, University Hospital Ramon y Cajal

Carretera de Colmenar Viejo, Km 9.100

ES-28034 Madrid (Spain)

E-Mail cristina.lozano@ hotmail.es 
(global longitudinal strain) could be seen (GLS\% $-14.6 \pm 5.0$ at baseline; $-15.7 \pm 5.1$ at discharge, $p=0.0116$ ), although restricted to patients in the CoreValve group; 1 year after the procedure, a greater improvement in GLS was observed (GLS\% $-17.1 \pm 4.9, p<0.001$ ), both in the CoreValve and the Lotus groups. Conclusions: Immediate and sustained improvement in GLS was appreciated after the TAVR procedure. Whether this finding continues to be noted in a more prolonged follow-up and its clinical implications need to be assessed in further studies.

(c) 2019 S. Karger AG, Basel

\section{Introduction}

Degenerative aortic stenosis (AS) is one of the most common cardiovascular diseases in developed countries, surpassed only by hypertension and coronary artery disease, and the most frequent valve disease requiring intervention [1], given that valve replacement is the only therapy that improves survival [2]. Moreover, the prevalence of this disease is increasing in ageing societies and so is the number of patients with associated comorbidities and high operative risk [1-3]. Over the past decade, transcatheter aortic valve replacement (TAVR) techniques have emerged as a novel therapeutic alternative for patients considered inoperable or high risk for surgery [46]. Since the first-in-man experience in 2002 [7], thousands of patients have been treated with this technique worldwide with a high procedural success rate [8].

Long-standing AS induces a series of adaptive responses to pressure overload that translate in changes in left ventricular (LV) geometry and performance, although LV volume and ejection fraction (LVEF) may remain preserved in advanced stages of the disease [9]. The most important changes observed include hypertrophic remodelling with increased myocardial fibrosis [10], abnormal LV compliance and diastolic dysfunction $[11,12]$, elevated end-diastolic pressure [13] and impaired contractility [14].

Echocardiography plays a central role in the success of a TAVR procedure, not only due to its importance in the pre-procedural evaluation, but also because it represents the best way for post-procedure follow-up.

Pre-procedurally, newer echocardiography methods like 2D speckle tracking analysis allow assessment of myocardial deformation as a sensitive marker for regional and global LV systolic function $[15,16]$. It has been reported that despite normal ejection fraction, LV myocardial deformation parameters such as global longitudi-

Left Ventricular Strain Improvement after TAVR nal strain may be altered, and its detection can have prognostic impact [17]. Strain imaging has demonstrated to be the most appropriate method to evaluate the subtle changes in systolic function that occur in patients with AS $[18,19]$ and global longitudinal strain (GLS) to be the most useful parameter to independently predict mortality [20]. Considering this, some ground-breaking working groups advocate for the use of GLS assessment as a tool for detecting high-risk asymptomatic patients that would benefit from an early valve intervention [21].

After valve replacement, TAVR has been associated with a faster and better recovery of LV function than surgical aortic valve replacement in patients with AS and reduced ejection fraction [22]. Nevertheless, while improvement in LV systolic function assessed by tissue Doppler and speckle tracking strain imaging has been observed after conventional surgical valve replacement in a mid- and long-term follow-up [14, 23-25], evidence about the benefits of TAVR in LV mechanics is scarce. TAVR leads to an immediate reduction in LV afterload without the confounding effects of major surgery. Recent studies have analysed LV function using strain imaging in patients after conventional TAVR implantation showing an improvement in LVEF and longitudinal systolic deformation at 1 year [26]. Others have also shown an acute regional improvement of myocardial systolic function measured by 2D strain analysis immediately after TAVR, with no significant changes in radial and circumferential functions or LVEF [27]. The acute haemodynamic effects of TAVR in LV diastolic performance, immediately after aortic valvuloplasty and prosthesis deployment have recently been assessed showing an improvement in LV diastolic function parameters $[28,29]$.

The main objective of this study was to assess the impact of TAVR on myocardial deformation parameters, both immediately after the procedure and in the long term. Additionally, we sought to evaluate the influence of the type of device on the evolution of myocardial deformation parameters and to identify potential predictive factors of favourable evolution on myocardial strain.

\section{Methods}

Study Population and Protocol

This observational study was conducted prospectively at 10 centres in Europe. Starting from October 2014 in the first participant centre until March 2015 in the last participant centre and during a period of 18 months, all consecutive patients with symptomatic severe AS undergoing TAVR with either a self-expanding CoreValve prosthesis (Medtronic, Minneapolis, MN, USA) or a 
Fig. 1. Study patient flow chart.

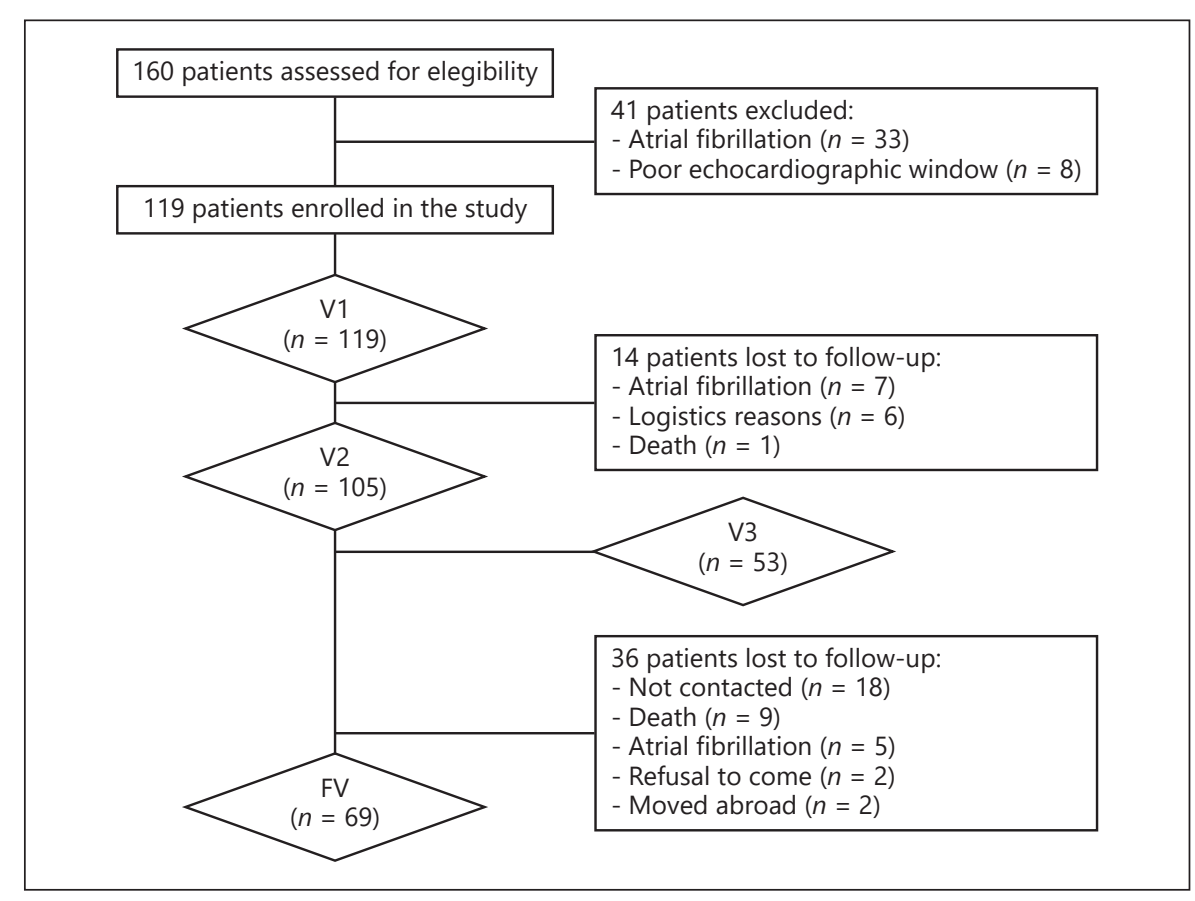

mechanically expanded Lotus prosthesis (Boston Scientific, Natick, MA, USA) were eligible for inclusion. Exclusion criteria were poor echocardiographic window, defined as two or more inadequately visualized myocardial segments (17-segment model), atrial fibrillation, the existence of a concomitant unstable cardiac condition, such as an acute coronary syndrome or significant pericardial effusion, or refusal to provide written informed consent.

An evaluation was planned at 3 points in time for all patients included in the study: a first visit (visit 1 or V1), prior to the procedure, generally scheduled between 24 and $48 \mathrm{~h}$ before the implantation; a second visit (visit 2 or V2), scheduled on the planned day of discharge; and a last visit (final visit or FV) 1 year after the procedure. Whenever possible, an intermediate visit (visit 3 or V3) was scheduled, approximately 6 months after the procedure. At each visit, patients underwent clinical and echocardiographic examination. All patients provided written informed consent. The study was approved by our ethics committee (CEIC code: 2013/049/20140731) and endorsed by the different committees at each participant centre.

Two-Dimensional Echocardiography

Echocardiographic examinations were performed using the available imaging equipment at each centre, provided that the same machine was used for all the examinations of any given patient. The ultrasound machines and softwares employed include: Vivid E9 (GE Medical Systems, Horten, Norway) with EchoPac software, version 113.0.0; iE33, HD11, EPIQ7 (Philips Medical Systems, Bothell, WA, USA) with QLAB software, version 10.0; and Acuson S2000 (Siemens Medical Solution, Mountain View, USA) with Velocity Vector Imaging, version 3.0. Digital loops were stored for off-line analysis, which was performed at each participant centre. The LV end-diastolic and end-systolic volumes were obtained at the standard apical 4-chamber and 2-chamber views, LVEF was calculated using Simpson's rule. GLS was computed from the apical 4-chamber, 2-chamber and 3-chamber views. Endocardial borders were traced by hand at an end-systolic and/or end-diastolic frame, according to the vendor, and myocardial speckles were automatically tracked throughout subsequent frames. Whenever necessary, tracking was manually corrected. GLS was obtained as the average value of regional strains. Absolute reduction (abGLS) and percentage change in GLS ( $\triangle$ GLS) were calculated between V2, V3 or FV and V1. Other classic systolic and diastolic parameters were collected according to current guidelines.

\section{Statistical Analysis}

All statistical analyses were performed using Stata 13.0. Continuous variables were expressed as mean \pm standard deviation and compared with Student's $t$ test. Qualitative variables were expressed as percentage and compared with the $\chi^{2}$ test. To assess differences in GLS, a paired $t$ test was used to compare pre- and postprocedural GLS at each point in time (this is, between V1 and V2, $\mathrm{V} 3$ or FV) and a 1-way repeated-measures ANOVA was run to determine whether there were differences in GLS along the different time points considered. The predictive role of various anthropometric and echocardiographic parameters was investigated by fitting a multivariable linear model with GLS(\%) at FV as the outcome. Possible explanatory outcomes were sex, gender, mean aortic gradient, aortic valve area, GLS(\%) at baseline, LVEF at V1, indexed mass of LV, LV end-diastolic volume, left atrial volume, mitral calcification and type of valve used.

\section{Results}

\section{Patient Baseline Characteristics}

The patient flow chart is presented in Figure 1. A total of 160 patients who underwent transcatheter aortic valve 
Table 1. Baseline characteristics, including a comparison between patients receiving a CoreValve and a Lotus prosthesis

\begin{tabular}{|c|c|c|c|c|}
\hline & Global & CoreValve & Lotus & $p$ value \\
\hline \multicolumn{5}{|c|}{ Anthropometric and clinical variables } \\
\hline Age, years & $81.2 \pm 6.9$ & $83.9 \pm 4.9$ & $79.7 \pm 7.4$ & 0.0013 \\
\hline Sex female, $\%$ & 50.4 & 55.8 & 47.4 & ns \\
\hline Weight, kg & $69 \pm 12.5$ & $68.2 \pm 13.6$ & $69.4 \pm 11.9$ & ns \\
\hline Height, cm & $161.6 \pm 9.2$ & $159.1 \pm 8.0$ & $163.1 \pm 9.6$ & 0.0253 \\
\hline BSA (Dubois) & $1.73 \pm 0.18$ & $1.70 \pm 0.19$ & $1.75 \pm 0.18$ & ns \\
\hline Hypertension, \% & 74.8 & 90.7 & 63.3 & 0.002 \\
\hline Diabetes, \% & 22.3 & 20.9 & 23.3 & ns \\
\hline $\mathrm{CAD}, \%$ & 14.6 & 9.3 & 18.3 & ns \\
\hline NYHA III-IV, \% & 53.5 & 69.8 & 37.2 & 0.002 \\
\hline \multicolumn{5}{|l|}{ Echocardiograpahic variables } \\
\hline Mean gradient, $\mathrm{mm} \mathrm{Hg}$ & $46.3 \pm 15.0$ & $50.7 \pm 13.6$ & $43.8 \pm 15.2$ & 0.0159 \\
\hline Peak gradient, $\mathrm{mm} \mathrm{Hg}$ & $76.3 \pm 26.2$ & $84.9 \pm 27.5$ & $71.3 \pm 24.2$ & 0.0065 \\
\hline $\mathrm{AVA}, \mathrm{m}^{2}$ & $0.75 \pm 0.23$ & $0.67 \pm 0.16$ & $0.79 \pm 0.25$ & 0.0058 \\
\hline Indexed $\mathrm{AVA}, \mathrm{cm}^{2} / \mathrm{m}^{2}$ & $0.44 \pm 0.17$ & $0.43 \pm 0.21$ & $0.46 \pm 0.15$ & ns \\
\hline LVEDV, mL & $97.8 \pm 36.3$ & $103 \pm 34.7$ & $94.6 \pm 37.1$ & ns \\
\hline Indexed LVEDV, $\mathrm{mL} / \mathrm{m}^{2}$ & $56.5 \pm 19.1$ & $60.4 \pm 18.7$ & $54.2 \pm 19.1$ & ns \\
\hline LVEF, \% & $56 \pm 12.6$ & $55.5 \pm 11.5$ & $56.3 \pm 13.2$ & ns \\
\hline LV mass, $g$ & $250.0 \pm 80.4$ & $261.5 \pm 91.1$ & $243.1 \pm 73.0$ & ns \\
\hline Indexed LV mass, $\mathrm{g} / \mathrm{m}^{2}$ & $145.5 \pm 45.9$ & $154.8 \pm 54.1$ & $139.8 \pm 39.4$ & 0.0964 \\
\hline Significant LVH, \% & 68.1 & 69.8 & 67.1 & ns \\
\hline LAV, mL & $71.7 \pm 27.4$ & $69.6 \pm 30.5$ & $72.9 \pm 25.5$ & ns \\
\hline Indexed $\mathrm{LAV}, \mathrm{mL} / \mathrm{m}^{2}$ & $41.8 \pm 16.8$ & $41.1 \pm 20.0$ & $42.2 \pm 14.8$ & ns \\
\hline
\end{tabular}

BSA, body surface area; CAD, coronary artery disease; NYHA, New York Heart Association; AVA, aortic valve area; LVEDV, left ventricle end-diastolic volume; LVEF, left ventricle ejection fraction; LVH, left ventricle hypertrophy; LAV, left atrial volume. The figures in the fields show means \pm standard deviation for continuous variables and percentages for qualitative variables.

implantation at participant centres were assessed for eligibility. 41 patients $(25.6 \%)$ met the exclusion criteria, 33 of them because of atrial fibrillation prior to device implantation and 8 of them because of poor echocardiographic window and thus were not enrolled in the study. Of the 119 patients included in the study, 43 treated with a CoreValve and 76 treated with a Lotus device, 7 developed atrial fibrillation after valve implantation ( 2 of them transient and 5 of them permanent), 6 lacked a complete pre-discharge echocardiographic examination because of logistic reasons and 1 died shortly after the intervention, leaving a population of 105 patients for analysis at V2 (41 patients in the CoreValve group and 64 patients in the Lotus group). At the end of the study, 9 patients had died, 2 had moved to another county, 2 refused to attend the visit, 5 had atrial fibrillation and 18 could not be contacted, leaving a population of 69 patients for analysis at FV (37 patients in the CoreValve group and 32 patients in the Lotus group). Additionally, from the total population of
119 patients, 53 patients without atrial fibrillation had a complete echocardiographic examination at 6 months, which was used for an intermediate analysis at V3.

Patient baseline characteristics are summarized in Table 1. The median age was $81.2 \pm 6.9$ years and $50.4 \%$ were female. Concerning clinical data, $74.8 \%$ of patients had hypertension, $22.3 \%$ had diabetes mellitus and $14.6 \%$ had a history of coronary artery disease. More than half of the patients $(53.5 \%)$ presented poor functional class (considered as such a NYHA classification of III or IV).

All 119 patients had severe AS: the aortic valve area was $0.75 \pm 0.23 \mathrm{~cm}^{2}$, and the mean pressure gradient was $46.3 \pm 15.0 \mathrm{~mm} \mathrm{Hg}$. A reduced LVEF $(<50 \%)$ was found in 30 of 119 patients (25.2\%), with classical lowflow low-gradient state (LVEF $<50 \%$ and stroke volume index $<35 \mathrm{~mL} / \mathrm{m}^{2}$ ) seen in 2 of 119 patients $(1 \%)$ and paradoxical low-flow state (LVEF $\geq 50 \%$ and stroke volume index $\left.<35 \mathrm{~mL} / \mathrm{m}^{2}\right)$ seen in 1 of 119 patients $(0.8 \%)$. The indexed LV mass was $145.5 \pm 45.9 \mathrm{~g} / \mathrm{m}^{2}$, with 81 
Table 2. Evolution of echocardiographic parameters at each visit

\begin{tabular}{|c|c|c|c|c|c|c|c|}
\hline Mean gradient, $\mathrm{mm} \mathrm{Hg}$ & $46.3 \pm 15.0$ & $12 \pm 7.9$ & $<0.001$ & $11.7 \pm 7.8$ & $<0.001$ & $11.7 \pm 10.6$ & $<0.001$ \\
\hline Peak gradient, $\mathrm{mm} \mathrm{Hg}$ & $76.3 \pm 26.2$ & $21.6 \pm 12.8$ & $<0.001$ & $21.6 \pm 13.3$ & $<0.001$ & $21.7 \pm 17.3$ & $<0.001$ \\
\hline $\mathrm{AVA} / \mathrm{EOA}, \mathrm{m}^{2}$ & $0.75 \pm 0.23$ & $1.94 \pm 0.59$ & $<0.001$ & $1.86 \pm 0.67$ & $<0.001$ & $1.68 \pm 0.56$ & $<0.001$ \\
\hline Indexed AVA/EOA, $\mathrm{cm}^{2} / \mathrm{m}^{2}$ & $0.44 \pm 0.17$ & $1.12 \pm 0.36$ & $<0.001$ & $1.07 \pm 0.41$ & $<0.001$ & $1.02 \pm 0.34$ & $<0.001$ \\
\hline LVEF, \% & $56 \pm 12.5$ & $56.8 \pm 11.5$ & ns & $61.4 \pm 10.0$ & 0.0260 & $57.8 \pm 11.8$ & ns \\
\hline Indexed mass, $\mathrm{g} / \mathrm{m}^{2}$ & $145.5 \pm 45.9$ & $132.3 \pm 41.3$ & 0.0009 & $123.2 \pm 33.5$ & 0.0001 & $120.1 \pm 37.2$ & 0.0002 \\
\hline $\mathrm{LAV}, \mathrm{mL}$ & $71.7 \pm 27.4$ & $64.8 \pm 25.2$ & 0.0339 & $67.8 \pm 29.9$ & 0.0965 & $64.4 \pm 26.7$ & 0.0528 \\
\hline Indexed $\mathrm{LAV}, \mathrm{mL} / \mathrm{m}^{2}$ & $41.8 \pm 16.8$ & $37.7 \pm 16.4$ & 0.0853 & $39.7 \pm 17.6$ & 0.0838 & $39.3 \pm 16.2$ & ns \\
\hline GLS, \% & $-14.6 \pm 5.0$ & $-15.7 \pm 5.1$ & 0.0116 & $-18.1 \pm 4.7$ & 0.0004 & $-17.1 \pm 4.9$ & $<0.001$ \\
\hline
\end{tabular}

V1, visit 1; V2, visit 2; V3, visit 3; FV, final visit; AVA, aortic valve area; EOA, effective orifice area; LVEDV, left ventricle end-diastolic volume; LVEF, left ventricle ejection fraction; LAV, left atrial volume; GLS, global longitudinal strain. The figures in the fields show means \pm standard deviation for continuous variables and percentages for qualitative variables.

patients (68.1\%) having significant (moderate or severe) LV hypertrophy (considering $\geq 132 \mathrm{~g} / \mathrm{m}^{2}$ for men and $\geq 109 \mathrm{~g} / \mathrm{m}^{2}$ in women as the cut-off for moderate hypertrophy).

\section{Evolution of AS Severity, Chamber Volumes, LV \\ Mass and Function and Myocardial Deformation \\ Parameters}

The first echocardiographic examination (V1) was performed a median of 1 (1-2) days prior to the intervention, the second (V2) a median of 5 (4-7) days after the procedure, the intermediate (V3) a median of 188 (183-195) days after the intervention and the last examination (FV) 370 (366-377) days after the procedure.

The echocardiographic parameters measured at each visit are listed in Table 2. Predictably, parameters of AS severity suffered a profound change 1 year after the TAVR procedure, with a significant decrease in transvalvular gradients (mean aortic gradient from $46.3 \pm 15.0$ to $11.7 \pm 10.6 \mathrm{~mm} \mathrm{Hg}, p<0.001$; peak aortic gradient from $76.3 \pm 26.2$ to $21.7 \pm 17.3 \mathrm{~mm} \mathrm{Hg}, p<0.001)$ and a significant increase in aortic valve area (from $0.75 \pm 0.23$ to $\left.1.68 \pm 0.56 \mathrm{~cm}^{2}, p<0.001\right)$. A significant reduction in $\mathrm{LV}$ indexed mass was also noted (from $145.5 \pm 45.9$ to $120.1 \pm 37.2 \mathrm{~g} / \mathrm{m}^{2}, p=0.0002$ ). Nevertheless, systolic function as assessed by LVEF measured by the Simpson biplane method remained unaltered (from $56 \pm 12.5$ to $57.8 \pm 11.8 \%, p=0.3911)$. In contrast with this, GLS showed a progressive and statistically significant reduction throughout the examinations $(-14.6 \pm 5.0 \%$ at V1;
$-15.7 \pm 5.1 \%$ at $\mathrm{V} 2, p=0.0116 ;-18.1 \pm 4.7 \%$ at $\mathrm{V} 3, p=$ $0.0004 ;-17.1 \pm 4.9 \%$ at $\mathrm{FV}, p<0.001)$. This improvement was seen both in the group of patients with low ejection fraction at baseline (defined as $<50 \%$ by the Simpson biplane method), which showed GLS of $-10.9 \pm 4.1 \%$ at V1, $-12.1 \pm 4.3 \%$ at V2, $p=0.0265,-14.6 \pm 5.6$ at V3, $p=0.19$, and $-14.2 \pm 5.5$ at FV, $p=0.141$, and in the group of patients with normal ejection fraction, which showed GLS of $-16.5 \pm 4.5$ at $\mathrm{V} 1,-17.2 \pm 4.8$ at $\mathrm{V} 2, p=0.1506,-19.3 \pm 4.1$ at V3, $p=0.120$, and $-18.3 \pm 4.2$ at FV, $p=0.0002$.

The results of the 1-way repeated-measures ANOVA showed that GLS was statistically different over the course of the study, $F(3,233)=11.01(p<0.0001)$.

\section{Evolution of AS Severity, Chamber Volumes and LV}

Mass and Function according to Type of Valve

Differences in baseline parameters were presented in Table 1. Differences in echocardiographic parameters at each examination according to valve subtype are shown in Table 3.

Notably, a slightly superior decrease in transaortic gradients and increase in effective orifice area were seen in the CoreValve group, while LV end-diastolic volume, LVEF, indexed mass and left atrial volume were comparable between groups at each examination.

\section{Evolution of LV Mechanics Improvement according to} Type of Valve

In a longitudinal subgroup analysis, a differential behaviour in GLS evolution could be appreciated ac- 
Table 3. Differences in echocardiographic parameters at each examination according to valve subtype

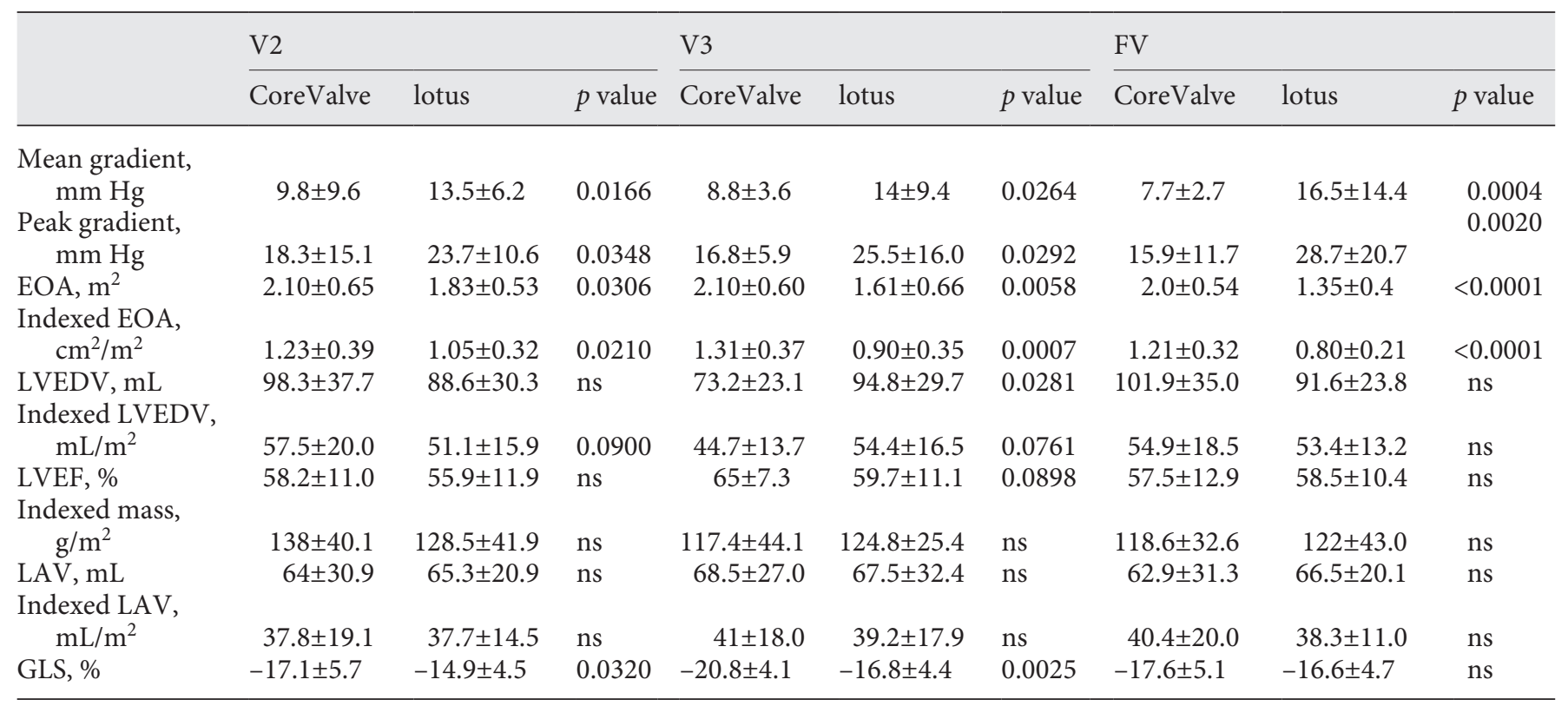

V2, visit 2; V3, visit 3; FV, final visit; EOA, effective orifice area; LVEDV, left ventricle end-diastolic volume; LVEF, left ventricle ejection fraction; LAV, left atrial volume; GLS, global longitudinal strain. The figures in the fields show means \pm standard deviation for continuous variables and percentages for qualitative variables.

Table 4. Evolution of global longitudinal strain (\%) according to valve subtype

\begin{tabular}{|c|c|c|c|c|c|c|c|}
\hline & V1 & V2 & $\begin{array}{l}p \text { value } \\
(\mathrm{V} 1-\mathrm{V} 2)\end{array}$ & V3 & $\begin{array}{l}p \text { value } \\
(\mathrm{V} 1-\mathrm{V} 3)\end{array}$ & $\mathrm{FV}$ & $\begin{array}{l}p \text { value } \\
(\mathrm{V} 1-\mathrm{FV})\end{array}$ \\
\hline CoreValve & $-14.3 \pm 5.0$ & $-17.1 \pm 5.7$ & $<0.0001$ & $-20.3 \pm 4.6$ & 0.0010 & $-17.6 \pm 5.1$ & $<0.0001$ \\
\hline Lotus & $-14.8 \pm 5.0$ & $-14.9 \pm 4.9$ & ns & $-16.7 \pm 4.4$ & 0.0775 & $-16.5 \pm 4.6$ & 0.0176 \\
\hline Global & $-14.6 \pm 5.0$ & $-15.7 \pm 5.1$ & $<0.0116$ & $-18.1 \pm 4.7$ & 0.0004 & $-17.1 \pm 4.9$ & $<0.0001$ \\
\hline
\end{tabular}

V1, visit 1; V2, visit 2; V3, visit 3; FV, final visit. The figures in the fields show means \pm standard deviation.

cording to valve subtype (Table 4). In the CoreValve group, an immediate significant improvement in GLS could be noted at V2, with a further significant decrease in consecutive examinations $(-14.3 \pm 5.0 \%$ at $\mathrm{V} 1 ;-17.1 \pm 5.7 \%$ at $\mathrm{V} 2, p<0.0001 ;-20.3 \pm 4.6 \%$ at V3, $p=0.0010 ;-17.6 \pm 5.1 \%$ at $\mathrm{FV}, p<0.0001)$. The 1 -way repeated-measures ANOVA showed a statistically significant improvement in GLS along the different time points, $F(3,95)=11.86(p<0.0001)$. In the Lotus group, a gradual reduction in GLS could be seen throughout the examinations, only achieving a significant reduction 1 year after valve replacement $(-14.8 \pm 5.0 \%$ at $\mathrm{V} 1 ;-14.9 \pm 4.9 \%$ at $\mathrm{V} 2, p=0.9155 ;-16.7 \pm 4.4$ at V3, $p=0.0775 ;-17.1 \pm 4.9 \%$ at FV, $p<0.0001)$. The 1 -way

Left Ventricular Strain Improvement after TAVR repeated-measures ANOVA showed a statistically significant improvement in GLS along the different time points, $F(3,135)=2.89(p=0.0380)$. If compared transversally, a statistically significant difference in GLS between valve subtypes could be seen at V2 and V3, but not at FV (Table 3).

Figure 2 presents box plots of GLS at each visit for each valve subtype. The effective orifice area after TAVR was calculated using postimplantation LV outflow tract diameter, LV outflow tract velocity-time integrals with the pulsed-wave Doppler sample volume at the proximal edge of the valve stent and velocity-time integrals across the prosthesis measured by continuous-wave Doppler sonography. 


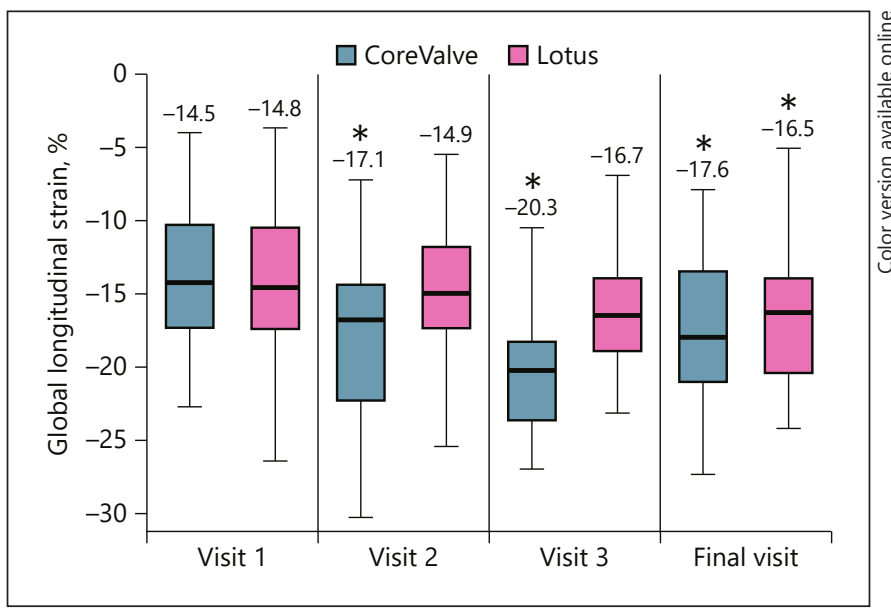

Fig. 2. Evolution of global longitudinal strain by valve subtype. The figure shows boxplots for global longitudinal strain (\%) for each valve subtype at each study visit. ${ }^{*} p<0.05$ : statistically significantly different from visit 1.

Table 5. Multiple linear regression

\begin{tabular}{lcc}
\hline Variables & $\begin{array}{l}\text { B coefficient } \\
\text { (standard error) }\end{array}$ & $p$ value \\
\hline GLS (\%) at baseline & $-0.355(0.0866)$ & $<0.01$ \\
Mean aortic gradient & $0.0803(0.0278)$ & $<0.01$ \\
Type of valve (Lotus) & $-2.019(0.815)$ & $<0.05$ \\
Mitral calcification (yes) & $1.845(0.893)$ & $<0.05$ \\
\hline
\end{tabular}

Multiple $R^{2} 0.360$. Probability $>F<0.0001$.

Prediction of GLS Improvement according to Baseline Characteristics

A multiple regression was run to predict the difference in GLS at FV, including various anthropometric and echocardiographic parameters obtained at V1. After a stepwise regression, GLS at baseline, type of valve used, mean aortic gradient and presence of significant mitral calcification were found to best predict GLS at FV. These variables statistically significantly predicted the difference in GLS (\%) at FV, F $(4,83)=11.58, p<0.0001, R^{2}=$ 0.3583 . All four variables added statistically significantly to the prediction, $p<0.05$. The variables included in the final model and their statistical significance are shown at Table 5. A graphic representation of the relationship between GLS and the continuous variables included in the model (GLS at baseline and valve subtype) can be seen in Figures 3 and 4.

\section{Discussion}

The main findings of this study are as follows: (i) TAVR is associated with an immediate and sustained improvement in LV mechanics, as demonstrated by GLS reduction, (ii) this occurs although LV systolic function, as assessed by LVEF by Simpson's biplane method, remains unaltered, (iii) the profile of GLS improvement differs between valve subtype, with only the CoreValve group showing a statistically significant reduction in GLS immediately after device implantation and both the CoreValve and the Lotus group ensuring a statistically significant reduction in GLS 1 year after valve replacement.

\section{Patient Population}

We think the population included in the study accurately represents that of severe AS patients usually referred for a TAVR procedure, with similar characteristics to the population included in the intermediate-risk patient study [30, 31].

\section{Effect of TAVR in LV Geometry}

Severe AS causes a chronic pressure overload that leads to a pathological remodelling in the form of concentric hypertrophy, with an increase in LV mass and myocardial fibrosis. TAVR causes an acute and sustained decrease in transvalvular gradient that could favour reverse remodelling. An immediate reduction in indexed LV mass was also seen, a finding also seen in previous studies, both with TAVR and surgical replacement [32-34]. Given that this change could hardly be explained by changes in myocyte size or number, protein synthesis, organization of the sarcomere or fibrosis, we propose that this change could represent a reduction in myocardial oedema, as seen in myocarditis [35]. In our opinion, this could represent the first landmark of an incipient reverse remodelling.

\section{Effect of TAVR in LV Performance}

In this study, with a follow-up of 1 year and 2 intermediate echocardiographic examinations, no change was noted in systolic function, which was largely normal prior to the procedure, but an otherwise significant reduction in GLS was seen.

In a stratified analysis according to valve subtype, the Lotus group showed a delayed improvement in GLS compared to the CoreValve group, reaching a statistically significant longitudinal difference only at FV, but without significant differences between the two groups at the end of the study. This finding could be ex- 


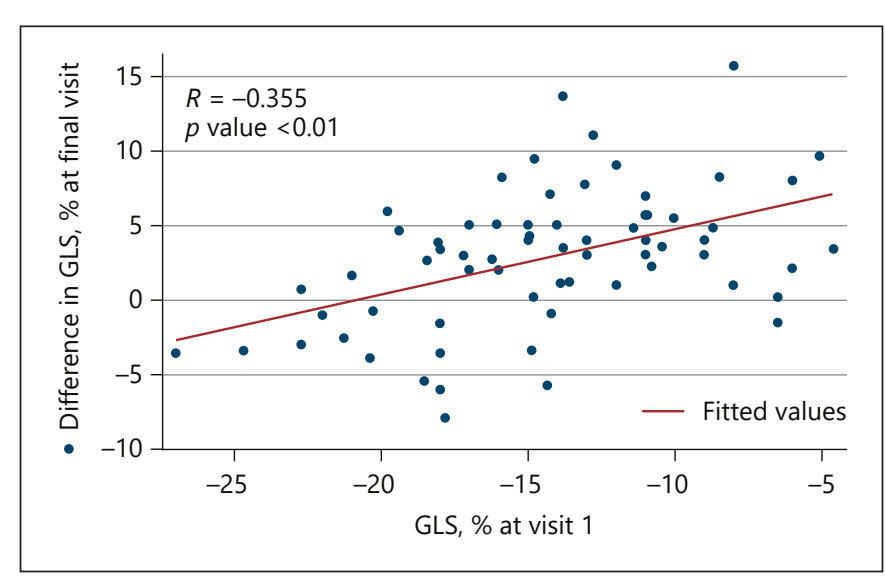

Fig. 3. Graphic representation of the relationship between the difference in global longitudinal strain (GLS; \%) at final visit and GLS at visit 1 .

plained by the lightly superior reduction in transaortic gradients and increment in effective orifice area obtained by the CoreValve, which may facilitate an improvement in LV performance earlier at follow-up. This, in turn, could be explained by the different architecture of both prostheses, which confers a supravalvular position of the prosthetic leaflets in the case of the CoreValve which may help maximize the effective orifice area.

\section{Limitations of the Study}

The main limitations of this analysis are the relatively small sample size and the lack of randomization between the groups.

Radial and circumferential strain values were not collected in the study, mainly because GLS is more widespread and reproducible, so we considered it to be the more relevant parameter of LV mechanics for clinical application. Thus, potential changes in radial and circumferential deformation could not be studied.

We decided to consider all GLS data available, regardless of the echocardiographic machine employed at each centre, provided that the same machine was used for every study in the same patient, and so, 5 different scanners from 3 different manufacturers were used. Although inter-vendor variability makes it difficult to directly compare a given GLS value between two different machines because of the different algorithms used by the manufacturers, studies comparing strain measurements among different vendors have found only small variations from one to another [36]. With that in mind, we expected that the procedure would elicit an improvement in GLS of the

Left Ventricular Strain Improvement after TAVR

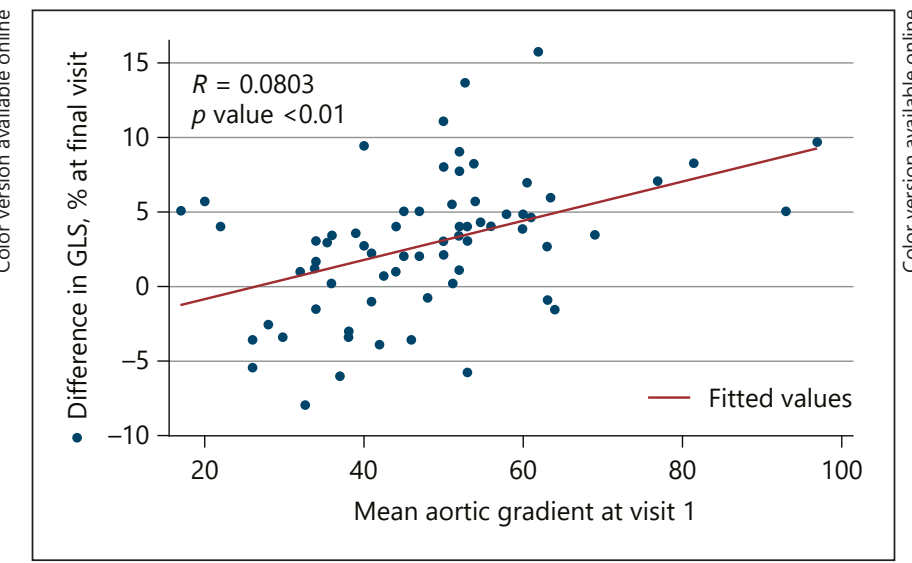

Fig. 4. Graphic representation of the relationship between the difference in global longitudinal strain (GLS; \%) at final visit and mean aortic gradient at visit 1 .

same magnitude for every vendor used that would overcome this obstacle. However, we do not know whether our findings could represent an underestimation of the effect of TAVR over GLS if a single vendor was employed.

\section{Conclusions}

Although LVEF remained unaltered after TAVR, an immediate and sustained improvement in GLS could be appreciated. This evolution of changes in LV mechanics was different between valve subtypes, with an earlier reduction of GLS in the CoreValve group, although the Lotus group proved a similar benefit 1 year after TAVR. Whether this finding continues to be noted in a more prolonged follow-up and its clinical implications need to be assessed in further studies.

\section{Statement of Ethics}

All procedures performed in studies involving human participants were in accordance with the ethical standards of the institutional research committee and with the 1964 Helsinki declaration and its later amendments or comparable ethical standards. Informed consent was obtained from all individual participants included in the study.

\section{Disclosure Statement}

All authors declare that they have no conflict of interest regarding the publication of this article. 


\section{Funding Sources}

This study was funded by a non-conditioned grant from Boston Scientific, Natick, MA, USA.

\section{Author Contributions}

Vanesa Cristina Lozano Granero: concept and design, data collection, data analysis and interpretation, drafting article, statistics.

Sara Fernández Santos: data collection, data analysis and interpretation, critical revision and approval of article.

Covadonga Fernández-Golfín: concept and design, data collection, critical revision and approval of article.

Ariana González Gómez: concept and design, data collection, critical revision and approval of article.

María Plaza Martín: data collection, data analysis and interpretation, critical revision and approval of article.
Jesús María de la Hera Galarza: data collection, critical revision and approval of article.

Francesco Fulvio Faletra: data collection, critical revision and approval of article.

Martin J. Swaans: data collection, critical revision and approval of article.

Teresa López-Fernández: data collection, critical revision and approval of article.

Dolores Mesa: data collection, critical revision and approval of article.

Giovanni La Canna: data collection, critical revision and approval of article.

Tomás Echeverría García: data collection, critical revision and approval of article.

Gilbert Habib: data collection, critical revision and approval of article.

Amparo Martínez Monzonís: data collection.

José Luis Zamorano Gómez: concept and design.

\section{References}

1 Nkomo VT, Gardin JM, Skelton TN, Gottdiener JS, Scott CG, Enriquez-Sarano M. Burden of valvular heart diseases: a population-based study. Lancet. 2006 Sep;368(9540):1005-11.

2 Schwarz F, Baumann P, Manthey J, Hoffmann M, Schuler G, Mehmel HC, et al. The effect of aortic valve replacement on survival. Circulation. 1982 Nov;66(5):1105-10.

3 Carabello BA, Paulus WJ. Aortic stenosis. Lancet. 2009 Mar;373(9667):956-66.

4 Leon MB, Smith CR, Mack M, Miller DC, Moses JW, Svensson LG, et al; PARTNER Trial Investigators. Transcatheter aortic-valve implantation for aortic stenosis in patients who cannot undergo surgery. N Engl J Med. 2010 Oct;363(17):1597-607.

5 Smith CR, Leon MB, Mack MJ, Miller DC, Moses JW, Svensson LG, et al.; PARTNER Trial Investigators. Transcatheter versus surgical aortic-valve replacement in high-risk patients. N Engl J Med. 2011 Jun;364(23):2187-98.

6 Zajarias A, Cribier AG. Outcomes and safety of percutaneous aortic valve replacement. J Am Coll Cardiol. 2009 May;53(20):1829-36.

7 Cribier A, Eltchaninoff $\mathrm{H}$, Bash A, Borenstein N, Tron C, Bauer F, et al. Percutaneous transcatheter implantation of an aortic valve prosthesis for calcific aortic stenosis: first human case description. Circulation. 2002 Dec; 106(24):3006-8.

8 Himbert D, Descoutures F, Al-Attar N, Iung B, Ducrocq G, Détaint D, et al. Results of transfemoral or transapical aortic valve implantation following a uniform assessment in high-risk patients with aortic stenosis. J Am Coll Cardiol. 2009 Jul;54(4):303-11.

9 Ross J Jr. Afterload mismatch and preload reserve: a conceptual framework for the analysis of ventricular function. Prog Cardiovasc Dis. 1976 Jan-Feb;18(4):255-64.
10 Gerdts E. Left ventricular structure in different types of chronic pressure overload. Eur Heart J Suppl. 2008;10 suppl E:E23-30.

11 Chang SA, Park PW, Sung K, Lee SC, Park SW, Lee YT, et al. Noninvasive estimate of left ventricular filling pressure correlated with early and midterm postoperative cardiovascular events after isolated aortic valve replacement in patients with severe aortic stenosis. J Thorac Cardiovasc Surg. 2010 Dec;140(6): 1361-6.

12 Dahl JS, Videbæk L, Poulsen MK, Pellikka PA, Veien K, Andersen LI, et al. Noninvasive assessment of filling pressure and left atrial pressure overload in severe aortic valve stenosis: relation to ventricular remodeling and clinical outcome after aortic valve replacement. J Thorac Cardiovasc Surg. 2011 Sep; 142(3):e77-83.

13 Aronow WS. Valvular aortic stenosis in the elderly. Cardiol Rev.2007 Sep-Oct;15(5):217-25.

14 Delgado V, Tops LF, van Bommel RJ, van der Kley F, Marsan NA, Klautz RJ, et al. Strain analysis in patients with severe aortic stenosis and preserved left ventricular ejection fraction undergoing surgical valve replacement. Eur Heart J. 2009 Dec;30(24):3037-47.

15 Leitman M, Lysyansky P, Sidenko S, Shir V, Peleg E, Binenbaum M, et al. Two-dimensional strain-a novel software for real-time quantitative echocardiographic assessment of myocardial function. J Am Soc Echocardiogr. 2004 Oct;17(10):1021-9.

16 Reisner SA, Lysyansky P, Agmon Y, Mutlak D, Lessick J, Friedman Z. Global longitudinal strain: a novel index of left ventricular systolic function. J Am Soc Echocardiogr. 2004 Jun; 17(6):630-3.

17 Yingchoncharoen T, Gibby C, Rodriguez LL, Grimm RA, Marwick TH. Association of myocardial deformation with outcome in asymptomatic aortic stenosis with normal ejection fraction. Circ Cardiovasc Imaging. 2012 Nov;5(6):719-25.

18 Weidemann F, Jamal F, Sutherland GR, Claus P, Kowalski M, Hatle L, et al. Myocardial function defined by strain rate and strain during alterations in inotropic states and heart rate. Am J Physiol Heart Circ Physiol. 2002 Aug;283(2):H792-9.

19 Weidemann F, Jamal F, Kowalski M, Kukulski T, D'Hooge J, Bijnens B, et al. Can strain rate and strain quantify changes in regional systolic function during dobutamine infusion, B-blockade, and atrial pacing-implications for quantitative stress echocardiography. J Am Soc Echocardiogr. 2002 May; 15(5): $416-24$.

20 Kusunose K, Goodman A, Parikh R, Barr T, Agarwal S, Popovic ZB, et al. Incremental prognostic value of left ventricular global longitudinal strain in patients with aortic stenosis and preserved ejection fraction. Circ Cardiovasc Imaging. 2014 Nov; 7(6):938-45.

21 Dahl JS, Magne J, Pellikka PA, Donal E, Marwick TH. Assessment of Subclinical Left Ventricular Dysfunction in Aortic Stenosis. JACC Cardiovasc Imaging. 2019 Jan;12(1):163-71.

22 Bauer F, Coutant V, Bernard M, Stepowski D, Tron C, Cribier A, et al. Patients with severe aortic stenosis and reduced ejection fraction: earlier recovery of left ventricular systolic function after transcatheter aortic valve implantation compared with surgical valve replacement. Echocardiography. 2013 Sep;30(8):865-70.

23 Chen Y, Zhang Z, Cheng L, Fan L, Wang C, Shu X. The Early Variation of Left Ventricular Strain after Aortic Valve Replacement by Three-Dimensional Echocardiography. PLoS One. 2015 Oct;10(10):e0140469. 
24 Rost C, Korder S, Wasmeier G, Wu M, Klinghammer L, Flachskampf FA, et al. Sequential changes in myocardial function after valve replacement for aortic stenosis by speckle tracking echocardiography. Eur J Echocardiogr. 2010 Aug;11(7):584-9.

25 Lindqvist P, Bajraktari G, Molle R, Palmerini E, Holmgren A, Mondillo S, et al. Valve replacement for aortic stenosis normalizes subendocardial function in patients with normal ejection fraction. Eur J Echocardiogr. 2010 Aug;11(7):608-13.

26 Løgstrup BB, Andersen HR, Thuesen L, Christiansen EH, Terp K, Klaaborg KE, et al. Left ventricular global systolic longitudinal deformation and prognosis 1 year after femoral and apical transcatheter aortic valve implantation. J Am Soc Echocardiogr. 2013 Mar; 26(3):246-54.

27 Schattke S, Baldenhofer G, Prauka I, Zhang K, Laule M, Stangl V, et al. Acute regional improvement of myocardial function after interventional transfemoral aortic valve replacement in aortic stenosis: a speckle tracking echocardiography study. Cardiovasc Ultrasound. 2012 Mar;10(1):15.

28 Gonçalves A, Marcos-Alberca P, Almeria C, Feltes G, Rodríguez E, Hernández-Antolín
RA, et al. Acute left ventricle diastolic function improvement after transcatheter aortic valve implantation. Eur J Echocardiogr. 2011 Oct;12(10):790-7.

29 Spethmann S, Dreger H, Baldenhofer G, Stüer K, Saghabalyan D, Müller E, et al. Short-term effects of transcatheter aortic valve implantation on left atrial mechanics and left ventricular diastolic function. J Am Soc Echocardiogr. 2013 Jan;26(1):64-71.e2.

30 Leon MB, Smith CR, Mack MJ, Makkar RR, Svensson LG, Kodali SK, et al.; PARTNER 2 Investigators. Transcatheter or Surgical Aortic-Valve Replacement in Intermediate-Risk Patients. N Engl J Med. 2016 Apr;374(17): 1609-20.

31 Humphries KH, Toggweiler S, Rodés-Cabau J, Nombela-Franco L, Dumont E, Wood DA, et al. Sex differences in mortality after transcatheter aortic valve replacement for severe aortic stenosis. J Am Coll Cardiol. 2012 Sep; 60(10):882-6.

32 Douglas PS, Hahn RT, Pibarot P, Weissman NJ, Stewart WJ, Xu K, et al. Hemodynamic outcomes of transcatheter aortic valve replacement and medical management in severe, inoperable aortic stenosis: a longitudinal echocardiographic study of cohort B of the
PARTNER trial. J Am Soc Echocardiogr. 2015;28(2):210-17.e1-9.

33 Dobson LE, Musa TA, Uddin A, Fairbairn TA, Swoboda PP, Erhayiem B, et al. Acute Reverse Remodelling After Transcatheter Aortic Valve Implantation: A Link Between Myocardial Fibrosis and Left Ventricular Mass Regression. Can J Cardiol. 2016 Dec;32(12): 1411-8.

34 Shin S, Park PW, Han WS, Sung KI, Kim WS, Lee YT. Mass reduction and functional improvement of the left ventricle after aortic valve replacement for degenerative aortic stenosis. Korean J Thorac Cardiovasc Surg. 2011 Dec;44(6):399-405.

35 Zagrosek A, Wassmuth R, Abdel-Aty H, Rudolph A, Dietz R, Schulz-Menger J. Relation between myocardial edema and myocardial mass during the acute and convalescent phase of myocarditis-a CMR study. J Cardiovasc Magn Reson. 2008 Apr;10(1): 19.

36 Farsalinos KE, Daraban AM, Ünlü S, Thomas JD, Badano LP, Voigt JU. Head-to-head comparison of global longitudinal strain measurements among nine different vendors. J Am Soc Echocardiogr. 2015 Oct;28(10):1171-81. e2. 